\title{
List of Tables
}

Tab. 1.1 Chain transfer constants of solvent and counterion - 12

Tab. 1.2 Effect of polar material on chain transfer reaction - 13

Tab. 1.3 Partial solvent dielectric constant and electron donation index -17

Tab. 1.4 Effect of solvent polarity on rate constant of styrene anion polymerization - 17

Tab. 1.5 The product of MMA polymerization initiated with butyllithium -22

Tab. 1.6 Effect of lithium salt additives on MMA anionic polymerization -22

Tab. 1.7 Anionic polymerization of MMA in the presence of crown ethers - 23

Tab. 1.8 Anionic polymerization of different methacrylate -24

Tab. $1.9 \quad \mathrm{pK}_{\mathrm{d}}$ value of several anionic polymerized monomers -33

Tab. 1.10 The cationic living polymerization system of styrene and its derivative monomers -42

Tab. 1.11 The effect of vanadium initiator on propylene initiating activity and regularity of products -55

Tab. 2.1 Examples of group transfer polymerization -74

Tab. 2.2 Results of group transfer polymerization of VBM/MMA -76

Tab. 3.1 St bulk polymerization using a novel photoinitiated transfer terminator - 102

Tab. 3.2 Examples of structurally controllable polymers prepared by RAFT polymerization — 115

Tab. 8.1 The basic structural parameters of diamond, graphite, and $\mathrm{C}_{60}-272$

Tab. 8.2 The main peaks of IR, Raman, NMR, and UV-VIS of $\mathrm{C}_{60}$ and $\mathrm{C}_{70}-273$

Tab. 8.3 The solubility parameters and solubility of $\mathrm{C}_{60}$ in different solvents -274

Tab. 8.4 Superconductivity of fullerenes and their critical temperatures -275 
